\title{
Karakteristik Biodiesel dari Minyak Biji Randu (Ceiba Pentandra) dengan Proses Transesterifikasi Menggunkan Katalis NaoH
}

\author{
Nofal Kharis ${ }^{1 *}$, Hary Sutjahjono ${ }^{2)}$, Hari Arbiantara2), \\ Digdo Listyadi Setyawan'), Nasrul IIminnafik ${ }^{2)}$ \\ 1)Alumni Jurusan Teknik Mesin Fakultas Teknik Universitas Jember, Jl. Kalimantan 37, Jember, 68121 \\ 2)Jurusan Teknik Mesin Fakultas Teknik Universitas Jember, Jl. Kalimantan 37, Jember, 68121 \\ Naskah diterima 28/01/2019; direvisi 08/04/2019; disetujui 25/04/2019 \\ doi: https://doi.org/10.24843/JEM.2019.v12.i01.p07
}

\begin{abstract}
Abstrak
Indonesia sangat berpotensi untuk produksi bahan bakar biodiesel yang berbahan nabati dengan keunggulan yaitu bisa diperbaharui. Banyak sumber bahan bakar alternatif yang mudah ditemukan di Indonesia untuk dijadikan bahan pembuatan biodiesel salah satunya biji randu. Pembuatan biodiesel dari bahan minyak biji randu yang diperoleh dengan cara biji randu dikeringkan terlebih dahulu kemudian biji dihancurkan dan haluskan menggunakan mesin penggiling, kemudian setelah biji halus hasil dari penggilingan dipress untuk mendapatkan minyaknya. Ektraksi biji kapuk menghasilkan 16-25 \% ml minyak biji randu dari berat biji. Proses degumming dengan cara minyak ditimbang kemudian dipanaskan dengan suhu mencapai $\pm 50{ }^{\circ} \mathrm{C}$, Kemudian di tambahkan asam phospat sebanyak $0,1 \%$ dari berat minyak randu. Dengan suhu minyak dipertahankan selama 60 menit. Kemudian proses transesterifikasi dilakukan pencampuran larutan pada suhu $50{ }^{\circ} \mathrm{C}$ dengan lama pengadukan 90 menit, proses transesterifikasi menggunakan larutan metanol dan $\mathrm{NaoH}$ sebebagai katalis untuk menghasilkan metyl ester. Kemudian biodiesel diuji karakteristiknya dari pengujian menghasilkan nilai kalor $8641,473 \mathrm{kal} / \mathrm{gram}$, densitas $8730 \mathrm{~g} / \mathrm{cm}^{3}$, viskositas $6.815 \mathrm{cst}$, flash point $115^{\circ} \mathrm{C}$.
\end{abstract}

Kata kunci: biodiesel, transesterifikasi, minyak biji randu

Abstract

Indonesia has the potential for the production of biodiesel fuels made from vegetables with many advantages, which can be renewed. There are many alternative fuel sources that are easily found in Indonesia to make biodiesel as one of the ingredients for seedling. The making of biodiesel from the ingredients of linseed oil obtained by means of litter seeds is dried first then the seeds are crushed and puree using a grinding machine, then after the fine seeds from the mill are pressed to get the oil. Extraction of kapok seeds produces $16-25 \% \mathrm{ml}$ of seed oil from seed weight. The Degumming process by weighing the oil is then heated with temperatures reaching $\pm 50^{\circ} \mathrm{C}$, then phosphate acid is added as much as $0.1 \%$ of the weight of the oil. With the oil temperature maintained for 60 minutes. Then the transesterification process was carried out by mixing the solution at $50^{\circ} \mathrm{C}$ with a stirring time of 90 minutes, the transesterification process using methanol and $\mathrm{NaoH}$ as a catalyst to produce metyl ester. Then the characteristics of the biodiesel tested from the test produced a heating value of $8641,473 \mathrm{cal} / \mathrm{gram}$, density $8730 \mathrm{~g} / \mathrm{cm} 30$, viscosity $6,815 \mathrm{cst}$, flash point $115^{\circ} \mathrm{C}$.

Keywords: biodiesel, transesterifikasi, ceiba pentandra

\section{Pendahuluan}

Pertambahan populasi penduduk manusia dari tahun ke tahun kebutuhan akan pemenuhan energi di semua sektor secara nasional semakin meningkat [1]. Minyak bumi konsumsi di Indonesia dengan tingkat konsumsi sangat tinggi maka dalam waktu 60 tahun mendatang akan habis. Untuk mengantisipasi hal tersebut perlu adanya energi alternatif yang bersifat renewable (dapat diperbaharui) salah satu sumber bahan bakar sebagai bahan bakar alternatif bisa menjadi solusi permasalahan tersebut adalah biodiesel [2].

Biodiesel didefinisikan sebagai metyl ester dariiasam lemak rantai panjang yang berasal dari bahannbaku terbarukan seperti minyak biji bijian atau lemak hewani. Biodiesel sebagai bahan bakar yang dapat digunakan dalam mesin diesel [3].

Bahan bakar biodiesel adalah bahan bakar bersih, biodegradable, tidak beracun dan memiliki profil emisi gas yang rendah, ramah lingkungan. Jadi sangat bermanfaat bagi lingkungan. Penggunaan biodiesel memiliki potensi untuk mengurangi tingkat polutan dan potensi karsinogen [4,5].

Minyak kelapa sawit, minyak kedelai, minyak kacang, minyak kemiri, minyak randu, minyak nyamplung, minyak jarak merupakan bahan untuk pembuatan biodiesel yang dihasilkan dari minyak tumbuh tumbuhan yang terdapat di Indonesia [6]. Namun, pengunaan dari minyak tumbuhan ini sebagai bahan produk biodiesel akan bersaing dengan produk makanan. Maka dari itu pengunaan minyak tumbuhan yang tidak dapat dimakan seperti contohnya minak biji randu sebagai sumber alternatif untuk pembuatan biodiesel.

Ada beberapa macam biji penghasil minyak yang tidak dapat dimakan yang bisa digunakan sebagai sumber untuk bahan produksi biodiesel yaitu, minyak 
biji nyamplung, biji kepuh, biji jarak, biji randu, yang terutama tumbuh di iklim tropis dan sub-tropis $[7,8]$.

Indonesia memiliki tanaman kapuk yang bisa dimanfaatkan bijinya, Menurut Lengen hiem menyatakan bahwa dalam 1 ha tanaman pohon kapuk randu dengan usia pohon \pm 17 tahun dapat menghasilkan $\pm 500 \mathrm{~kg}$ buah kapuk dan bisa menghasilkan \pm 1 ton biji randu kering. Tiap gelondong dari buah kapuk mengandung $26 \%$ biji randu sehingga tiap $\pm 100 \mathrm{~kg}$ gelondong bisa menghasilkan $\pm 26 \mathrm{~kg}$ biji randu [9].

Pohon kapuk randu bisa dimanfaatkan untuk pembuatan lemari, furniter, triplek, dan bahan sebagai pembuatan kertas. Serat kapuk dimanfaaatkan sebagai bahan pembuatan matras, kasur, akan tetapi pada biji randu sebagian masih belum dimanfaatkan dengan maksimal. Biji kapuk yang belum termanfaatkan bisa dimanfaatkan sebagai bahan baku untuk pembuatan biodiesel [10].

\section{Metode Penelitian}

\subsection{Proses pembuatan}

Metode pada penelitian ekperimental menggunakan dua tahap yaitu tahap pembuatan biodiesel dan tahap pengujian karakteristik dari biodiesel. Bahan yang digunakan dari pohon kapuk randu di wilayah Kecamatan Besuk Kabupaten Probolinggo. Biji randu yang digunakan merupakan biji randu yang sudah kering dan tua. Pengambilan sampel dilakukan secara acak biji yang diambil dianggap mewakili dari biji randu terbaik yang ada di wilayah Probolinggo. Biji randu ini dikeringkan dibawah sinar matahari kurang lebih 7 hari. Alat yang digunakan untuk mendapatkan minyak menggunakan alat press dengan kekuatan press hidrolik 20 ton untuk mengeluarkan minyak dari hasil biji randu. Setelah menjadi biodiesel tahap pengujian karakteristik dari biodiesel minyak biji randu dengan pengujian nilai kalor menggunakan alat alat Bomb Calori dengan spesifikasi Merk mesin PAAR dengan model PAAR 1241 EF mengggunakan volt 220, negara pembuat USA Tahun pembuatan 1987. Pengujian karakteristik densitas menggunakan alat aerometer dengan gelas ukur 250 ml. Pengujian karakteristik viskositas menggunakan alat Herzog Saybolt dengan spesifikasi alat merk LEYBOLD dengan model ABR NL 90212 menggunakan volt 220 dan 55000 Watt, negara pembuat Jerman tahun pembuatan 1987. Dan pengujian karakteristik flash point menggunakan alat flash point tester dengan spesifikasi spesifikasi alat merk LEYBOLD dengan model ABR NL 90212 menggunakan volt 220 dan 420 Watt, negara pembuat Jerman tahun pembuatan 1987.

\subsection{Proses Pembuatan Biodiesel}

Tahapan yang dilakukan pada proses pembuatan biodiesel yaitu proses pengepresan biji randu, proses degumming minyak biji randu, transesterifikasi, pemisahan dan pemurnian biodiesel yang dihasilkan.

\subsection{Proses Pengepresan}

Biji yang sudah dihaluskan dengan cara digiling untuk memisahkan kulit cangkangnya dari biji supaya halus, biji yang sudah halus ditimbang kemudian dimasukkan kedalam alat pengepresssan untuk mengeluarkan dan menghasilkan minyak biji randunya.

\subsection{Proses Degumming}

Degumming merupakan proses untuk menghilangkan getah dan sisa sisa zat pengotor yang ada didalam minyak yang tidak diperlukan dalam pembuatan biodiesel dengan cara minyak ditimbang kemudian dipanaskan dengan suhu mencapai $\pm 50{ }^{\circ} \mathrm{C}$ diaduk menggunakan alat magnetic stirrer. Kemudian di tambahkan asam phospat sebanyak $1 \%$ dari berat minyak randu. Dengan suhu minyak dipertahankan selama 60 menit. Kemudian, minyak telah terpisah dimasukkan kedalam corong pemisah untuk dipisahkan antara minyak dan sisa pengotor yang mengendap [11].

\subsection{Proses Transesterifikasi}

Setelah mendapatkan senyawa metyl ester melalui proses degumming selanjutnya adalah proses transesterifikasi bertujuan untuk mengubah asamasam lemak dari trigliserida dalam bentuk metyl ester. Proses Transesterifikasi dimulai dengan minyak hasil proses degumming ditimbang terlebih dahulu kemudain dimasukkan ke dalam reaktor dan dipanaskan dengan suhu $\pm 50{ }^{\circ} \mathrm{C}$ setelah suhu tercapai, minyak diaduk kemudian menambahakan pelarut metanol sebanyak $20 \%$ dari berat minyak randu dan katalis $\mathrm{NaOH}$ seberat $1 \%$ dari berat minyak randu yang ditimbang. Dengan suhu larutan di pertahankan dengan waktu pengadukan 90 menit. Setelah itu produk yang sudah diproses didiamkan sehingga terbentuk suatu endapan. Kemudian di lanjutkan proses pemisahan dan pemurnian biodiesel.

\subsection{Pemurnian}

Selanjutnya dilakukan proses pencucian biodiesel dengan menambahkan sejumlah air panas lalu didiamkan selama 24 jam. Selanjutnya dilakukan proses pemurnian biodiesel dengan cara memanaskan biodiesel pada suhu $100^{\circ} \mathrm{C}$. Langkah tersebut dilakukan untuk semua perlakuan sehingga diperoleh biodiesel.

\section{Hasil dan Pembahasan}

\subsection{Gambar, Tabel dan Grafik}

Dari hasil minyak dari pengepressan biji randu yang sudah dihaluskan dengan cara digiling dapat dilihat pada tabel 1

\begin{tabular}{lll}
\multicolumn{3}{c}{ Tabel 1. Hasil Pengepressan minyak } \\
\hline Sample & Berat bahan & Hasil minyak \\
\hline A1 & 750 gram & $55 \mathrm{ml}$ \\
A2 & $750 \mathrm{gram}$ & $63 \mathrm{ml}$ \\
A3 & $750 \mathrm{gram}$ & $57 \mathrm{ml}$ \\
A4 & $750 \mathrm{gram}$ & $65 \mathrm{ml}$ \\
A5 & $750 \mathrm{gram}$ & $58 \mathrm{ml}$ \\
Rata rata & 750 gram & $59,6 \mathrm{ml}$ \\
\hline
\end{tabular}

Dari tabel diatas rata rata minyak yang diperoleh yaitu sebanyak $59,6 \mathrm{ml}$ pada berat bahan sebanyak 750 gram.

Setelah mendapatkan minyak dari hasil pengepresan kemudian dilakukan proses pembuatan biodiesel, didapatkan hasil dari rendemen dari proses pembuatan biodiesel dapat dilihat pada tabel 2 
Tabel 2. Rendemen Biodiesel Randu

\begin{tabular}{lcc}
\hline Sample & Bahan & Rendemen $\%$ \\
\hline A1 & 181,52 gram & 71,91 \\
A2 & 181,52 gram & 74,54 \\
A3 & 181,52 gram & 69,24 \\
A4 & 181,52 gram & 71,6 \\
Rata Rata & 181,52 gram & 71,82 \\
\hline
\end{tabular}

Dari tabel diatas rata rata rendemen dari biodiesel randu yang diperoleh sebanyak $71,82 \%$.

Biodiesel berikut ini merupakan perbandingan biodiesel dari minyak biji randu dengan biosolar SNI diproduksi oleh PT Pertamian Indonesia. Pengujian karakteristik meliputi nilai kalor, densitas, viskositas, dan flash point seperti pada Tabel 1.

Tabel 1. Karakteristik bahan bakar

\begin{tabular}{lccl}
\hline Karakteristik & $\begin{array}{c}\text { Biosolar } \\
\text { SNI }^{*}\end{array}$ & $\begin{array}{c}\text { Biodiesel } \\
\text { Randu }\end{array}$ & $\begin{array}{l}\text { Biodiesel } \\
\text { Alpukat }^{\star *}\end{array}$ \\
\hline $\begin{array}{l}\text { Nilai Kalor } \\
\text { (kal/gram) }\end{array}$ & 10.602 & 8.641 & 9.585 \\
$\begin{array}{l}\text { Densitas } \\
\left(\mathrm{kg} / \mathrm{m}^{3}\right)\end{array}$ & $815-890$ & 873 & 875 \\
$\begin{array}{l}\text { Viskositas } \\
\text { (cst) }\end{array}$ & $2,0-6,0$ & 6,8 & $3,7 \mathrm{~S}$ \\
Flash point $\left({ }^{\circ} \mathrm{C}\right.$ ) & Min 100 & 115 & 148 \\
\hline
\end{tabular}

Sumber

Biosolar *SNI PT Pertamina Indonesia [12].

Biodiesel Randu Nofal

Biodiesel **Alpukat Anawe dan Folayan [13].

Pada Tabel 1 ditunjukkan bahwa hasil dari penelitian karakteristik meliputi nilai kalor, viskositas, densitas dan flash point.

a. Nilai kalor merupakan jumlah panas yang ada dihasilkan dari pembakaran. Dengan hasil pengujian nilai kalor senilai $8.641 \mathrm{kal} / \mathrm{gram}$ nilai ini medekati nilai standar dimana standar yaitu $10.602 \mathrm{kal} / \mathrm{gram}$.

b. Densitas merupakan suatu besaran kerapatan massa benda satuan volume. Dengan hasil pengujian $873 \mathrm{~kg} / \mathrm{m} 3$. nilai ini masih memenuhi standart, dimana standart untuk densitas yaitu berkisar antara $815-890 \mathrm{~kg} / \mathrm{m} 3$.

c. Viskositas merupakan suatu angka yang menyatakan besarnya hambatan dari sutau bahan cair untuk mengalir atau ukuran dari besarnya tahanan gesek dari cairan. Hasil pengujian yang diperoleh yaitu 6.815 cst. nilai ini belum memenuhi standart, dimana standart untuk viskositas yaitu berkisar antara 2,3-6 cSt.

d. Flash Point merupakan angka nilai yang menyatakan suhu paling rendah dari bahan bakar untuk dapat terbakar. Hasil pengujian yang diperoleh yaitu $115{ }^{\circ} \mathrm{C}$. Nilai ini masih memenuhi standart, dimana standart untuk flash point yaitu dengan nilai minimal $100^{\circ} \mathrm{C}$.

Bahan bakar biodiesel biji randu memiliki nilai yang medekati dengan bahan bakar biosolar produksi PT Pertamina Indonesia.

Tabel 2. Nilai kalor Blending

\begin{tabular}{ccc}
\hline Blending & Komposisi & $\begin{array}{c}\text { Nilai Kalor } \\
\text { (Kal/gram) }\end{array}$ \\
\hline B0 & $0 \%$ biodiesel & 10.602 \\
B10 & $10 \%$ biodiesel & 10.474 \\
B20 & $20 \%$ biodiesel & 10.206 \\
B30 & $30 \%$ biodiesel & 10.124 \\
B100 & $100 \%$ biodiesel & 8.641 \\
\hline
\end{tabular}

Dengan hasil uji nilai kalor dari biodiesel dan biosolar murni, terlihat bahwa nilai kalor biodiesel lebih rendah dari biosolar dimana nilai kalor biosolar tanpa campuran biodiesel dengan nilai kalor $10.602 \mathrm{kal} / \mathrm{gram}$ dan nilai kalor biodiesel dengan nilai $8.642 \mathrm{kal} / \mathrm{gram}$. Nilai kalor blending terus menurun apabila dicampur bahan bakar dengan biodiesel.

\section{Simpulan}

Berdasarkan hasil dari penelitian maka dapat disimpulkan bahwa biodiesel yang dihasilkan telah memenuhi tiga standar mutu bahan bakar menurut SNI 7182:2015. Maka biodiesel ini bisa digunakan untuk menggantikan bahan bakar biosolar atau dengan mencampurkannya dengan bahan bakar yang diproduksi oleh PT Pertamina Indonesia.

\section{Ucapan Terima Kasih}

Kami mengucapkan terima kasih Lembaga Penelitian dan Pengabdian Masyarakat (LP2M) dan Fakultas Teknik Universitas Jember dalam kegiatan penelitian yang telah memberikan bantuan biaya.

\section{Daftar Pustaka}

[1] Amir, A. Saryono, Sri, N. dan Wahyuni. 2009. Faktor- Faktor yang mempengaruhi Produksi Biodiesel dari Minyak sawit Mentah menggunakan Katalis Padat Kalsium Karbonat Yang Dipijarkan. Jurnal Nature Indonesia. 1192): 129-134.

[2] Kuncahyo, P, A. Zuhdi., dan Semin. 2013. Analisa Prediksi Potensi Bahan Baku Biodiesel sebagai Suplemen Bahan Bakar Motor Diesel di Indonesia. (2) Vol. 2 ISSN: 2337-3539 Institut Teknologi Sepuluh Nopember.

[3] Meher, V. D. Sagar, S. N. Naik. 2006. Technical aspects of biodiesel production by transesterification - a review. J Renew Sustain Energy Rev. 2006, 10, 248-268.

[4] Demirbas .A, 2002. Biodiesel from vegetable oils via transesterification in supercritical methanol. Energy Conserv Manag. 2002, 43, 2349-2356.

[5] Heny, D. 2008. Potensi Minyak Biji Randu (Ceiba pentranda) Sebagai Alternatif Bahan Baku Biodiesel. Distilat-Jurnal Teknologi Separasi. 1. (2)

[6] Vasudevan, P. T. M. Briggs. 2008. Biodiesel production - current state of the art and challenges: A review. J Ind Microbiol Biotechnol. 2008, 35, 421-430, BioEnergy Special Issue.

[7] Tapanes, N. C., D. A. G. Aranda, J. W. de Mesquita,. 2008. Transesterification of Jatropha curcas oil glycerides: Theoretical and experimental studies of biodiesel reaction. Fuel. 2008, 87, 2286-2295.

[8] Openshaw, K. 2000. A review of Jatropha curcas: An oil plant of unfulfilled promises. Biomass Bioenergy. 2000, 19, 1-15.

[9] Norazahar, N. S., M. Yusup, M. Ahmad, S. A. Bakar dan J. Ahmad. 2012. Parametric Optimization of Kapok (Ceiba Pentandra) Oil Methyl Ester Production using Taguchi Approach. International Journal of Energy and Environment, Issue 6, Volume 6, 541-548.

[10] Erliyanti, N. K. 2016. Karakteristik biodiesel dari minyak biji randu (ceiba pentandra) pada reaktor batch berpengaduk bertekanan menggunakan 
katalis koh. Journal of Research and

Technologies, Vol. 2 No. 1.

[11] Sahirman. 2009. Perancangan Proses Produksi Biodiesel dari Minyak Biji Nyamplung (Calophyllum inophyllum). Disertasi Program Pasca Sarjana, IPB, Bogor.

[12] https://www.pertamina.com/industrialfuel/media/6 796/biosolar.pdf. [Diakses pada 4 Desember 2018].

[13] Anawe, A,. dan J. Adewale. 2018. Data on Optimization of Production Parameters on Persea Americana (Avocado) Plant Oil Biodiesel Yield and Quality. www.elsevier.com. S23523409(18)30916-8 